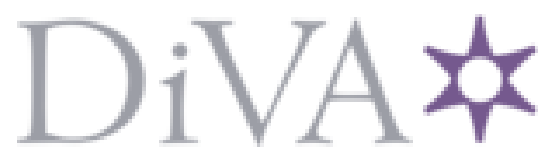

http://www.diva-portal.org

This is the published version of a paper published in International psychogeriatrics.

Citation for the original published paper (version of record):

Lövheim, H., Sandman, P., Karlsson, S., Gustafson, Y. (2008)

Behavioral and psychological symptoms of dementia in relation to level of cognitive impairment..

International psychogeriatrics, 20(4): 777-789

http://dx.doi.org/10.1017/S1041610208006777

Access to the published version may require subscription.

N.B. When citing this work, cite the original published paper.

Permanent link to this version:

http://urn.kb.se/resolve?urn=urn:nbn:se:umu:diva-23167 


\title{
Behavioral and psychological symptoms of dementia in relation to level of cognitive impairment
}

\author{
Hugo Lövheim, ${ }^{1}$ Per-Olof Sandman, ${ }^{2}$ Stig Karlsson ${ }^{1}$ \\ and Yngve Gustafson ${ }^{1}$ \\ ${ }^{1}$ Department of Community Medicine and Rehabilitation, Geriatric Medicine, Umeå University, Umeå, Sweden \\ ${ }^{2}$ Department of Nursing, Umeå University, Umeå, Sweden
}

ABSTRACT

Background: Many people with dementia exhibit some behavioral or psychological symptoms, e.g. aggressive or aberrant motor behavior, depression or hallucinations, at some time during the course of the disorder. The aim of the present study was to describe the probability of the occurrence of these symptoms of dementia in relation to the level of cognitive impairment.

Methods: 3404 people with cognitive impairment were selected from two large cross-sectional surveys of those in geriatric care settings, conducted in 1982 and 2000 in the county of Västerbotten, Sweden. Symptoms were assessed using the Multi-Dimensional Dementia Assessment Scale (MDDAS), subsumed with a rotated factor analysis, and investigated in relation to level of cognitive impairment, measured using the Gottfries cognitive scale.

Results: The passiveness factor had an almost linear correlation to the level of cognitive impairment $\left(\mathrm{r}^{2}=0.237\right)$. Non-linear correlations, with highest prevalences in middle-stage cognitive impairment, were found for aggressive behavior $\left(\mathrm{r}^{2}=0.057\right)$, wandering behavior $\left(\mathrm{r}^{2}=0.065\right)$, restless behavior $\left(\mathrm{r}^{2}=\right.$ $0.143)$, verbally disruptive/ attention-seeking behavior $\left(r^{2}=0.099\right)$, regressive/ inappropriate behavior $\left(r^{2}=0.058\right)$, hallucinatory symptoms $\left(r^{2}=0.021\right)$ and depressive symptoms $\left(\mathrm{r}^{2}=0.029\right)$.

Conclusion: The relations between the behavioral and psychological symptoms of dementia and level of cognitive impairment were non-linear, with higher prevalence rates in the middle stages of dementia, apart from the symptom of passiveness, which increased almost linearly with the severity of cognitive impairment.

Key words: BPSD, old age, aggression, depression, hallucinations, geriatric care, nursing home

Correspondence should be addressed to: H. Lövheim, Department of Community Medicine and Rehabilitation, Geriatric Medicine, Umeå University, SE-901 85 Umeå, Sweden. Phone: +46 9078588 59; Fax: +46 901306 23. Email: hugo.lovheim@germed.umu.se. Received 6 Sep 2007; revision requested 28 Nov 2007; revised version received 3 Dec 2007; accepted 6 Dec 2007. First published online 17 April 2008. 


\section{Introduction}

Dementia is a disorder characterized by multiple cognitive deficits. It is usually progressive and irreversible, and the most common forms are Alzheimer's type dementia and vascular dementia (American Psychiatric Association, 2000). In addition to cognitive decline, many of those with dementia exhibit some behavioral or psychological symptoms, e.g. aggressive or aberrant motor behavior, depression or hallucinations, at some time during the course of the disorder. The prevalence of such symptoms has been estimated to be between $79 \%$ and 92\% (Brodaty et al., 2001; Margallo-Lana et al., 2001). The behavioral and psychological symptoms of dementia (BPSD) cause much suffering for both the persons afflicted and their relatives and caregivers (Black and Almeida, 2004; Shin et al., 2005).

Various authors have proposed groupings of symptoms, and the distinctions between hyperactivity, psychosis, mood disturbances and apathy are fairly consistent (Mirakhur et al., 2004; Robert et al., 2005). Furthermore, many studies have investigated the prevalence of various symptoms along the line of progression of the dementia disorder. Apathy seems to be increasingly common as the dementia worsens (Mega et al., 1996; Spalletta et al., 2004; Shimabukuro et al., 2005; Selbaek et al., 2007). Aggressive behavior and aberrant motor behavior have also been found to correlate with increasing cognitive impairment (Mega et al., 1996; Harwood et al., 2000; Eustace et al., 2002; Holtzer et al., 2003; Suh and Kim, 2004; Engelborghs et al., 2005; Piccininni et al., 2005; Shimabukuro et al., 2005; Selbaek et al., 2007), but some studies have found a reduction of such behavior in the most severe stages (Sclan et al., 1996; Holtzer et al., 2003). There is no general agreement concerning hallucinations about whether there is a relationship with the level of cognitive impairment (Sclan et al., 1996; Harwood et al., 2000; Eustace et al., 2002; Suh and Kim, 2004; Craig et al., 2005; Piccininni et al., 2005; Selbaek et al., 2007) or not (Mega et al., 1996; Holtzer et al., 2003; Spalletta et al., 2004; Engelborghs et al., 2005; Shimabukuro et al., 2005; Lam et al., 2006). The findings regarding depressive symptoms are similar: some authors have found an increased prevalence with increased deterioration of dementia (Mega et al., 1996), some have found a decreased prevalence in severe dementia (Sclan et al., 1996; Holtzer et al., 2003), while many have not found any correlation (Harwood et al., 2000; Suh and Kim, 2004; Craig et al., 2005; Engelborghs et al., 2005; Piccininni et al., 2005; Shimabukuro et al., 2005; Selbaek et al., 2007). Finally some studies have found almost no correlation at all between behavioral and psychological symptoms and the level of cognitive impairment (Spalletta et al., 2004; Lam et al., 2006).

The picture of the symptoms also differs depending on type of dementia, e.g. hallucinations are more common in dementia with Lewy bodies while depression and emotional lability are more common in vascular dementia (Engelborghs et al., 2005; Chiu et al., 2006).

Studies that have investigated the relationship between behavioral and psychological symptoms and the level of cognitive impairment have hitherto been carried out only in small populations, and do not have the statistical power to investigate more exactly the relationship between the level of cognitive 
impairment and the probability of certain symptoms occurring. The aim of the present study was to describe the probability of the occurrence of BPSD in relation to the level of cognitive impairment.

\section{Method}

\section{Material}

The current analysis is based on two cross-sectional questionnaire surveys performed in 1982 and 2000 respectively in the county of Västerbotten in northern Sweden. The two surveys used the same methodology and the same questionnaire.

When the first investigation was conducted, the population in the area was 245,000 , of whom 38,000 (15.5\%) were older than 65 years, while by the time of the second investigation the population had increased to approximately 256,000 people, of whom 44,000 (17.2\%) were aged 65 years or older.

The number of people living in institutions providing geriatric care (nursing homes, residential care units, group dwellings for people with dementia, short-stay/rehabilitation units, somatic geriatric wards/somatic long-stay wards, psychogeriatric wards/long-stay wards (Kallin et al., 2004)) was 3910 in 1982 and 4357 in 2000 . The response rate was $92.3 \%$ and $87.3 \%$ respectively, rating 3607 and 3804 individuals respectively. Those who were younger than 65 years or for whom no age was registered were excluded from the analysis. Out of 3195 people from 1982 and 3669 from 2000, those who had a cognitive score that indicated cognitive impairment were selected. Thus 1369 persons were selected from the 1982 survey and 2035 from the 2000 survey, giving a total of 3404 people.

The study was approved by the Ethics Committee of the Faculty of Medicine at Umeå University (registration number 00-170).

\section{Procedures}

The assessments were made using the Multi-Dimensional Dementia Assessment Scale (MDDAS) (Sandman et al., 1988). The scale measures the level of functioning in activities of daily living (ADL), cognition and behavioral and psychological symptoms and also includes a registration of current drug prescriptions. The MDDAS has good inter- and intra-rater reliability (Sandman et al., 1988).

A form was sent to all the care settings, and the staff were asked to complete and return it to the researchers. The staff received written instructions about how to carry out the assessments and were informed that members of the research team could be contacted by phone to answer questions or provide additional guidance. The member of staff who knew the resident best was asked to fill in the assessment scales. Staff members were instructed that their assessments should be based on observations of the resident's state during the preceding week. 
Cognitive impairment was measured using a sub-scale developed by Gottfries and Gottfries (Adolfsson et al., 1981). The scale consists of 27 items measuring a person's level of cognitive functioning. A score of less than 24 is considered to indicate cognitive impairment, which correlates with a sensitivity of $90 \%$ and a specificity of $91 \%$ (Adolfsson et al., 1981) to the cut-off point 24/30 traditionally used in the Mini-mental State Examination (MMSE) (Folstein et al., 1975).

An ADL score was calculated based on the resident's ability to cope with dressing, hygiene, eating and bladder and bowel control. All ADL categories score 1-5, except that for bladder control, which scores $0-4$. Hence the ADL score varies from 4 to 24 , where a higher score indicates greater ADL independence.

The MDDAS contains 25 behavioral items and 14 psychological symptom items, which have been described in depth earlier (Sandman et al., 1988). Each item is rated on a three-point scale, indicating whether the symptom or behavior occurs at least once a day, once a week or never. The variables are dichotomized between at least once a week and less than once a week.

\section{Statistics and calculations}

The behavioral and the psychological symptom items of the MDDAS were reduced to fewer factors by means of a principal component analysis with a Varimax rotation. Factors with eigenvalues of above 1.00 were extracted, producing factors that conveyed meaningful information. The result is presented in Table 2. The first column shows the number of persons assessed as having displayed the behavior or symptom at least once a week. Each item is presented under the factor to which it loaded most. The model explained $53.4 \%$ of the total variance. The mean value of the items with a factor loading above 0.5 was calculated for each factor and the groups of variables were tested for internal consistency using Cronbach's $\alpha$ analysis. The $\alpha$ values ranged from 0.465 to 0.800 . The mean value of each factor was then plotted to investigate the relationship with level of cognitive impairment, and polynomial regression lines were fitted to the data (Figure 1). The $\mathrm{x}$ axis is the cognitive score (ranging from 23 to 0 ), the $y$ axis is the mean value of each factor, multiplied by 100 for convenience. First-, second- and third-degree terms were entered into a multivariate linear regression for each factor, and significant coefficients $(\mathrm{p}<$ 0.05) were used in the final regression model.

All data processing and statistical calculations were performed using the Statistical Package for Social Science SPSS ${ }^{\circledR}$ version 11.0 for Mac OS X and Microsoft ${ }^{\circledR}$ Excel $^{\circledR}$ version 10.3.

\section{Results}

The basic characteristics of the population are presented in Table 1 . The factor analysis produced nine factors, presented in Table 2 . Based on the contributing items the factors were labeled as wandering behavior, aggressive behavior, 
Table 1. Characteristics of residents

\begin{tabular}{lc}
\hline Cases, $\mathrm{n}$ & 3404 \\
Women, $\mathrm{n}(\%)$ & $2339(68.7)$ \\
Mean age \pm SD & $82.8 \pm 6.8$ \\
ADL score (4-24) mean \pm SD & $13.3 \pm 6.1$ \\
Cognitive score (0-27) mean \pm SD & $10.5 \pm 7.3$ \\
Walks independently, n (\%) & $1306(39.7)$ \\
Can rise from chair, n (\%) & $1936(56.9)$ \\
Impaired vision, n (\%) & $642(18.9)$ \\
Impaired hearing, n (\%) & $428(12.6)$ \\
Group dwelling, $\mathrm{n}(\%)$ & $608(17.9)$ \\
Nursing home, n (\%) & $1179(34.6)$ \\
Rehabilitation/short-stay unit, n (\%) & $29(0.9)$ \\
Residential care, n (\%) & $1108(32.5)$ \\
Somatic geriatric clinic, n (\%) & $272(8.0)$ \\
Psychogeriatric clinic, $\mathrm{n}(\%)$ & $208(6.1)$ \\
Anti-depressant (N06A) use, n (\%) & $972(28.6)$ \\
Minor tranquillizer/sedative (N05B \& C) use, n (\%) & $957(28.1)$ \\
Anti-psychotic drug (N05A) use, n (\%) & $1054(31.0)$ \\
Any psychotropic drug use, n (\%) & $2070(60.8)$ \\
\hline
\end{tabular}

$\mathrm{SD}=$ Standard Deviation, $\mathrm{ADL}=$ activities of daily living.

restless behavior, verbally disruptive/attention-seeking behavior, regressive/ inappropriate behavior, passiveness, hallucinatory symptoms and depressive symptoms. One factor consisted of only one item with a loading over 0.5, i.e. "Lies in other patient's beds." Since only $8.0 \%$ presented that symptom, the item was excluded from the subsequent analysis.

For each cognitive score the number of people assessed ranged from 99 to 159, except for 0 points where 194 people were assessed. Polynomial regression curves were fitted to the data (see Figure 1 and Table 3 ). The patterns were very similar for both data collections when analyzed separately (data not shown). The passiveness factor had an almost linear correlation to the level of cognitive impairment $\left(\mathrm{r}^{2}=0.237\right)$. Non-linear correlations were found for aggressive behavior $\left(\mathrm{r}^{2}=0.057\right)$, wandering behavior $\left(\mathrm{r}^{2}=0.065\right)$, restless behavior $\left(\mathrm{r}^{2}=0.143\right)$, verbally disruptive/attention-seeking behavior $\left(\mathrm{r}^{2}=0.099\right)$ and regressive/ inappropriate behavior $\left(\mathrm{r}^{2}=0.058\right)$. Still non-linear but weaker correlations were found for hallucinatory symptoms $\left(\mathrm{r}^{2}=0.021\right)$ and depressive symptoms $\left(\mathrm{r}^{2}=0.029\right)$. A consistent pattern was found in that the behavior or symptom was most common in the middle of the range of cognitive scores. The peak prevalences of wandering behavior and verbally disruptive/ attentionseeking behavior occurred at a higher cognitive score than aggressive behavior and restless behavior. All behaviors and symptoms, apart from passiveness, showed a decrease in prevalence in the lowest scores, corresponding to the final stages of dementia. This was most obvious for verbally disruptive/attentionseeking behavior. 


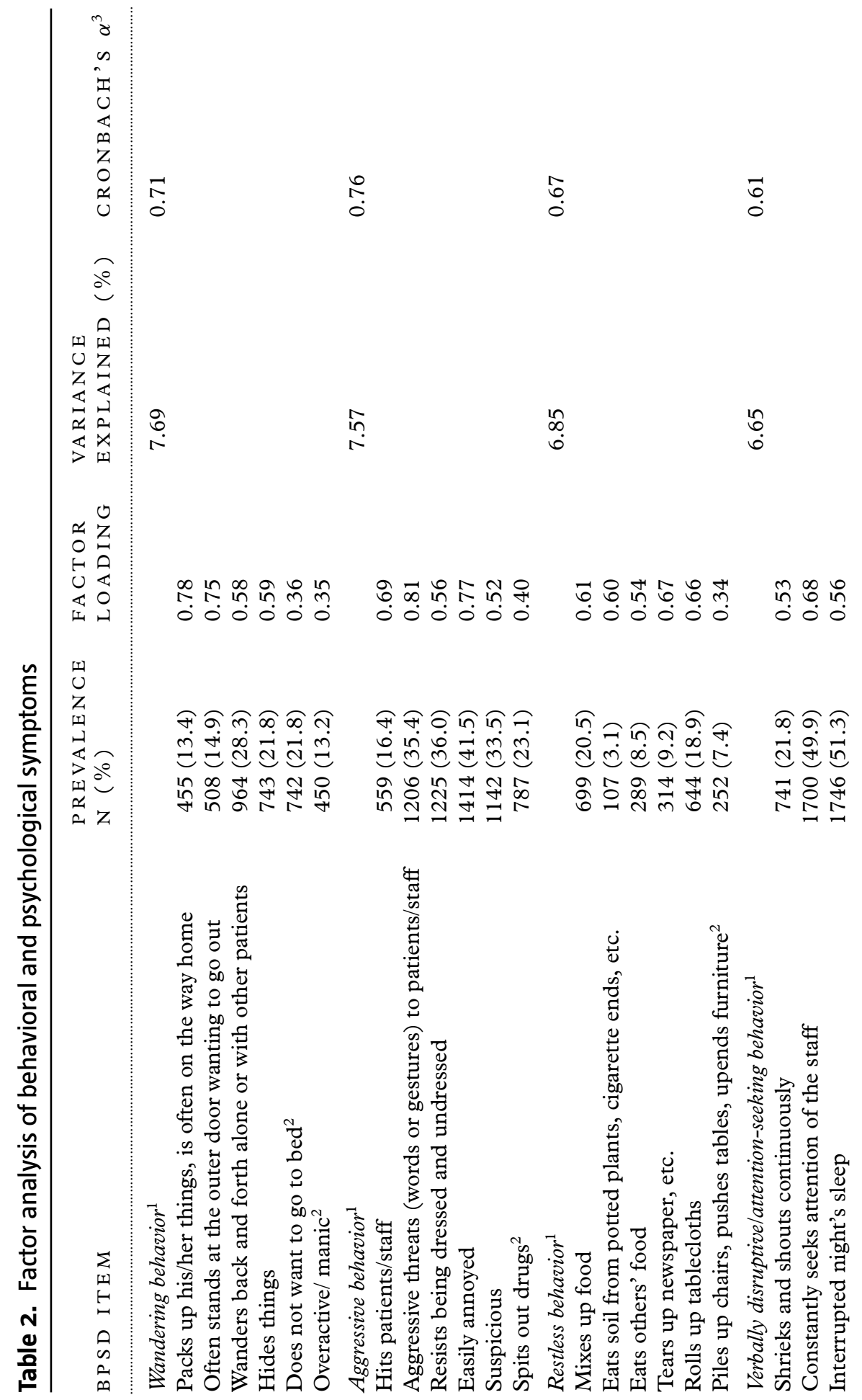




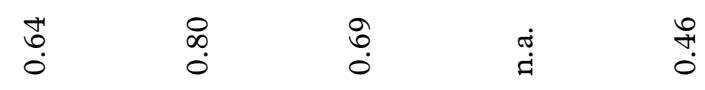

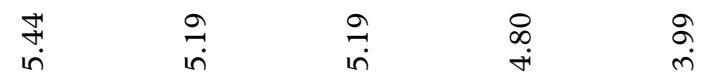

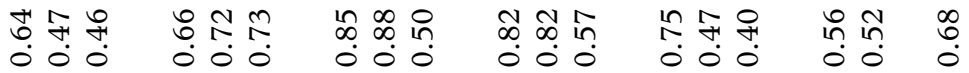

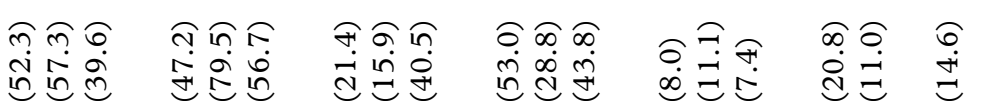

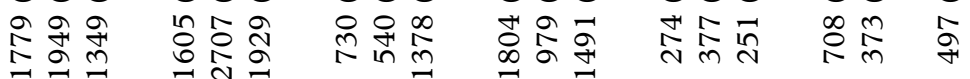

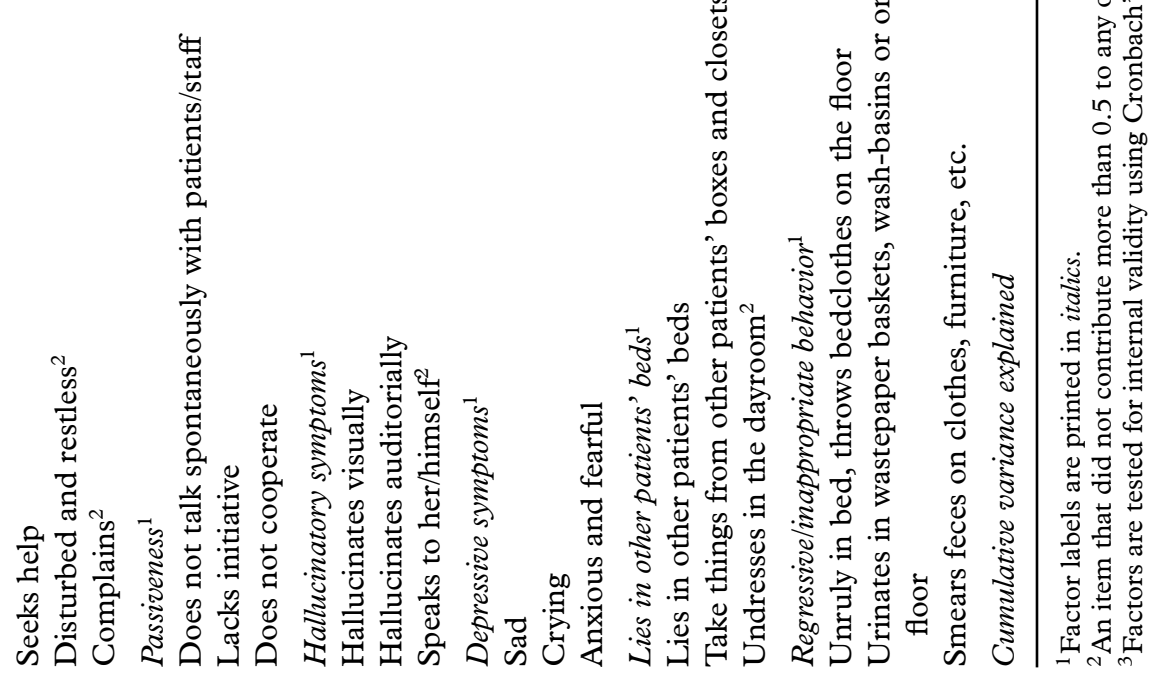


Wandering behavior

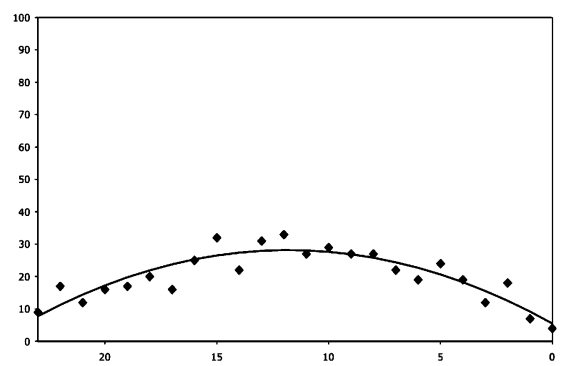

Aggressive behavior

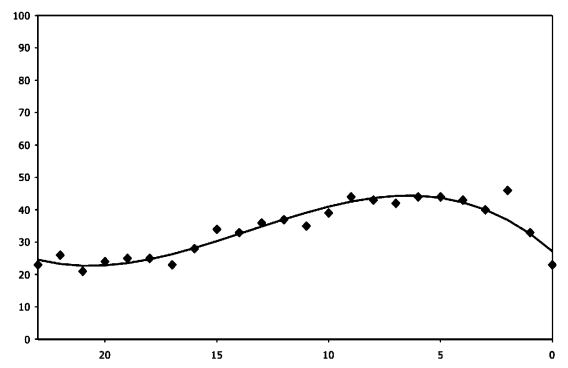

Restless behavior

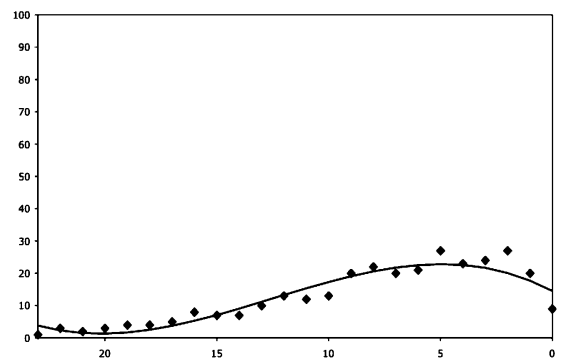

Verbally disruptive/ attention-seeking behavior

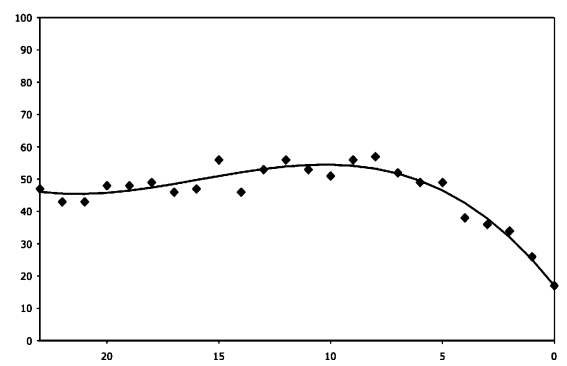

Passiveness

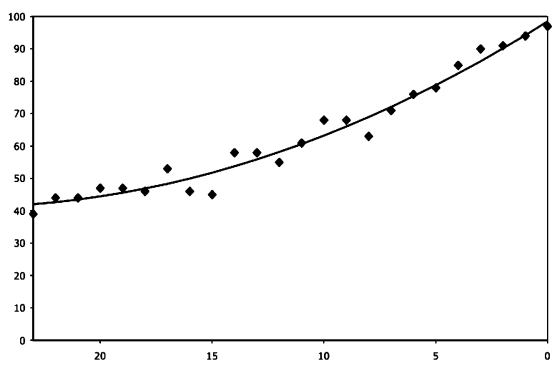

Hallucinatory symptoms

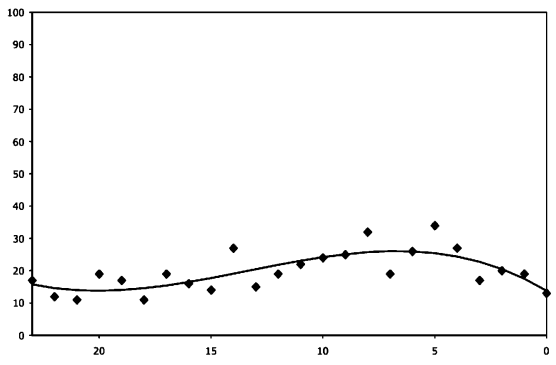

Depressive symptoms

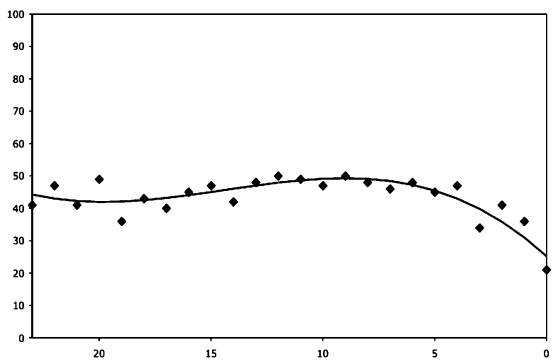

Regressive/ inappropriate behavior

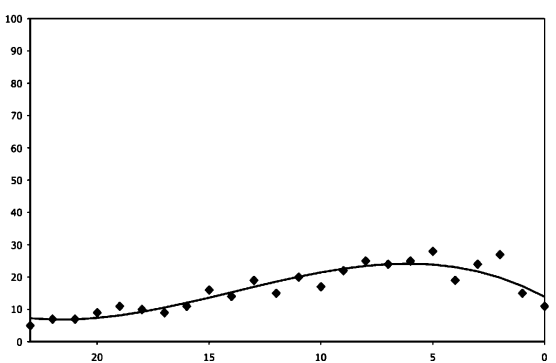

Figure 1. Behavioral and psychological symptoms in relation to level of cognitive impairment.

BPSD item (100 $\times$ mean of sum of contibuting factors) in relation to cognitive score, from 23 (mild cognitive impairment) to 0 (severe cognitive impairment). Polynomial regression curves are fitted to the data. Regression coefficients are presented in Table 3. 
Table 3. Regression curve characteristics of behavioral and psychological symptoms in relation to level of cognitive impairment

\begin{tabular}{|c|c|c|c|}
\hline BPSD ITEM & REGRESSION CURVE TYPE & $r^{2}$ & p-VALUE \\
\hline Wandering behavior & 2nd degree polynomial & 0.065 & $<0.001$ \\
\hline Aggressive behavior & 3rd degree polynomial & 0.057 & $<0.001$ \\
\hline Restless behavior & 3rd degree polynomial & 0.143 & $<0.001$ \\
\hline $\begin{array}{l}\text { Verbally disruptivel } \\
\text { attention-seeking behavior }\end{array}$ & 3rd degree polynomial & 0.099 & $<0.001$ \\
\hline Passiveness & 2nd degree polynomial & 0.237 & $<0.001$ \\
\hline Hallucinatory symptoms & 3rd degree polynomial & 0.021 & $<0.001$ \\
\hline Depressive symptoms & 3rd degree polynomial & 0.029 & $<0.001$ \\
\hline Regressive/ inappropriate behavior & 3rd degree polynomial & 0.058 & $<0.001$ \\
\hline
\end{tabular}

Note: The data in this table correspond to the diagrams in Figure 1.

\section{Discussion}

This study is, to the best of our knowledge, the first to explore the correlation between cognitive level and the prevalence of BPSD in a sample large enough to describe the non-linear relationships in more detail.

The study confirmed that apathy, or passiveness, is common and correlates strongly to the severity of cognitive impairment. The correlation between all the other factors of BPSD and the level of cognitive impairment was found to be significant and non-linear with the highest prevalence rates occurring at the middle stages of cognitive impairment. The findings were largely in agreement with those reported in the current literature, thus confirming earlier findings on the correlation between symptoms and cognitive level (Mega et al., 1996; Sclan et al., 1996; Harwood et al., 2000; Eustace et al., 2002; Holtzer et al., 2003; Spalletta et al., 2004; Suh and Kim, 2004; Craig et al., 2005; Engelborghs et al., 2005; Piccininni et al., 2005; Shimabukuro et al., 2005; Selbaek et al., 2007). Furthermore, the current findings also agree with common clinical experience.

The prevalence of the behaviors and symptoms declined in those with severe cognitive impairment. This could possibly be due both to reduced language and communication ability (e.g. in verbally disruptive/attention-seeking behavior) and to increasing difficulty on the part of the staff in interpreting symptoms of, for example, hallucinations. In late-stage dementia motor functions become affected and this could contribute, of course, to the reduced prevalence of certain behaviors, such as wandering and restlessness.

One important clinical implication of the finding that the prevalence of behavioral and psychological symptoms varies along with cognitive decline is that pharmacological treatment with, for example, anti-psychotics (Lövheim et al., 2006) needs to be regularly evaluated to check that the indication for treatment remains.

While most other studies have divided their sample into three groups (mild, moderate and severe dementia) or have investigated the linear correlation, 
our study with 24 different levels of cognitive impairment can describe the relationship more exactly. Sample sizes that are too small and groups that are too broad have probably contributed to the earlier, inconclusive findings regarding depressive symptoms and hallucinations in dementia. The statistical power of our study was good and the number of people assessed at each one of the 24 possible scores on the cognitive scale ranged from around 100 to just over 150 . At zero points nearly 200 people were assessed, indicating a floor effect of the scale. The instrument itself has previously been shown to have good, but not excellent, reliability. Uncertainties were, however, statistically compensated for by the large sample size. The use of data from 1982 is defensible mainly because it added another 1000 people to the investigation, and because dementia disorder supposedly was the same in 2000 as it was in 1982 .

Most other studies have used either the BEHAVE-AD scale (Reisberg et al., 1996) or the Neuropsychiatric Inventory (Cummings et al., 1994). The use of a different scale (the MDDAS; Sandman et al., 1988) in this study might, therefore, add new aspects to this research field, although it is obviously a weakness when it comes to comparability. Knowledge about non-cognitive aspects of dementia is still growing fast, and it is too early to restrict research to one single classification or diagnostic tool. This is reflected by the absence of these symptoms in the diagnostic manuals (American Psychiatric Association, 2000).

This study has some limitations. The prevalences presented were one-week prevalences and since many symptoms and behaviors tend to fluctuate, the probability of a symptom occurring in a person at some stage during the cognitive decline is probably higher. The prevalence rates were probably further affected by the fact that these behavioral and psychological symptoms might increase the risk of institutionalization. The selection effect has thus probably generated higher prevalence estimates than in a general population. Changes in the pharmacological and non-pharmacological treatment of behavioral and psychological symptoms might also have affected the prevalences, and have to be taken into account when interpreting the findings. The efficiency of the pharmacological treatment options available is modest, however (Schneider et al., 2006); their influence was therefore judged to be small. For a more profound discussion on pharmacological treatment and the differences between 1982 and 2000, see our earlier work (Lövheim et al., 2006; 2008). Another drawback is that no diagnosis of dementia was recorded, and the inclusion was based solely on the score of the Gottfries cognitive scale. However, the majority of those included in the study probably had a dementia disorder.

\section{Conclusion}

The relations between BPSD and level of cognitive impairment were non-linear, with higher prevalence rates in the middle stages of dementia, apart from the symptom of passiveness, which increased almost linearly with the severity of cognitive impairment. 


\section{Conflict of interest}

None.

\section{Description of authors' roles}

H. Lövheim undertook the acquisition, analysis and interpretation of the data, and the preparation of the manuscript. P. O. Sandman and S. Karlsson developed the study concept and design, and undertook acquisition of subjects and data, with S. Karlsson also undertaking the analysis and interpretation of data. Y. Gustafson was involved in the acquisition of subjects and data, analysis and interpretation of data, and the preparation of the manuscript. All authors reviewed the manuscript and approved the final version.

\section{Acknowledgements}

This study was supported financially by grants from the Umeå University Foundation for Medical Research, the Swedish Foundation for Healthcare Sciences and Allergy Research, the Field Research Center for the Elderly in Västerbotten, the Swedish Research Council, the Dementia Association of Sweden, and Erik and Anne-Marie Detlof's Foundation, Umeå University.

\section{References}

Adolfsson, R., Gottfries, C. G., Nystrom, L. and Winblad, B. (1981). Prevalence of dementia disorders in institutionalized Swedish old people. The work load imposed by caring for these patients. Acta Psychiatrica Scandinavica, 63, 225-244.

American Psychiatric Association (2000). Diagnostic and Statistical Manual of Mental Disorders, 4th edn (revised). Washington, DC: American Psychiatric Association.

Black, W. and Almeida, O. P. (2004). A systematic review of the association between the Behavioral and Psychological Symptoms of Dementia and burden of care. International Psychogeriatrics, 16, 295-315. DOI: 10.1017/S1041610204000468.

Brodaty, H. et al. (2001). Psychosis, depression and behavioural disturbances in Sydney nursing home residents: prevalence and predictors. International fournal of Geriatric Psychiatry, 16, 504-512. DOI: 10.1002/gps.382.

Chiu, M. J., Chen, T. F., Yip, P. K., Hua, M. S. and Tang, L. Y. (2006). Behavioral and psychologic symptoms in different types of dementia. Fournal of the Formosan Medical Association, 105, 556-562.

Craig, D., Mirakhur, A., Hart, D. J., McIlroy, S. P. and Passmore, A. P. (2005). A cross-sectional study of neuropsychiatric symptoms in 435 patients with Alzheimer's disease. American fournal of Geriatric Psychiatry, 13, 460-468.

Cummings, J. L., Mega, M., Gray, K., Rosenberg-Thompson, S., Carusi, D. A. and Gornbein, J. (1994). The Neuropsychiatric Inventory: comprehensive assessment of psychopathology in dementia. Neurology, 44, 2308-2314.

Engelborghs, S. et al. (2005). Neuropsychiatric symptoms of dementia: cross-sectional analysis from a prospective, longitudinal Belgian study. International fournal of Geriatric Psychiatry, 20, 1028-1037. DOI: 10.1002/gps.1395. 
Eustace, A. et al. (2002). A longitudinal evaluation of behavioural and psychological symptoms of probable Alzheimer's disease. International fournal of Geriatric Psychiatry, 17, 968-973. DOI: $10.1002 / g p s .736$.

Folstein, M. F., Folstein, S. E. and McHugh, P. R. (1975). "Mini-mental state": a practical method for grading the cognitive state of patients for the clinician. Fournal of Psychiatric Research, 12, 189-198.

Harwood, D. G., Barker, W. W., Ownby, R. L. and Duara, R. (2000). Relationship of behavioral and psychological symptoms to cognitive impairment and functional status in Alzheimer's disease. International fournal of Geriatric Psychiatry, 15, 393-400.

Holtzer, R. et al. (2003). Psychopathological features in Alzheimer's disease: course and relationship with cognitive status. Fournal of the American Geriatrics Society, 51, 953-960.

Kallin, K., Gustafson, Y., Sandman, P. O. and Karlsson, S. (2004). Drugs and falls in older people in geriatric care settings. Aging Clinical and Experimental Research, 16, 270-276.

Lam, L. C., Leung, T., Lui, V. W., Leung, V. P. and Chiu, H. F. (2006). Association between cognitive function, behavioral syndromes and two-year clinical outcome in Chinese subjects with late-onset Alzheimer's disease. International Psychogeriatrics, 18, 517-526. DOI: 10.1017/S1041610205002930.

Lövheim, H., Sandman, P. O., Kallin, K., Karlsson, S. and Gustafson, Y. (2006). Relationship between antipsychotic drug use and behavioral and psychological symptoms of dementia in old people with cognitive impairment living in geriatric care. International Psychogeriatrics, 18, 713-726. DOI: 10.1017/S1041610206003930.

Lövheim, H., Sandman, P. O., Kallin, K., Karlsson, S. and Gustafson, Y. (2008). Symptoms of mental health and psychotropic drug use among old people in geriatric care: changes between 1982 and 2000. International fournal of Geriatric Psychiatry (in press: epub ahead of print). DOI: $10.1002 / \mathrm{gps} .1876$.

Margallo-Lana, M. et al. (2001). Prevalence and pharmacological management of behavioural and psychological symptoms amongst dementia sufferers living in care environments. International fournal of Geriatric Psychiatry, 16, 39-44.

Mega, M. S., Cummings, J. L., Fiorello, T. and Gornbein, J. (1996). The spectrum of behavioral changes in Alzheimer's disease. Neurology, 46, 130-135.

Mirakhur, A., Craig, D., Hart, D. J., McLlroy, S. P. and Passmore, A. P. (2004). Behavioural and psychological syndromes in Alzheimer's disease. International fournal of Geriatric Psychiatry, 19, 1035-1039. DOI: 10.1002gps.1203.

Piccininni, M., Di Carlo, A., Baldereschi, M., Zaccara, G. and Inzitari, D. (2005). Behavioral and psychological symptoms in Alzheimer's disease: frequency and relationship with duration and severity of the disease. Dementia and Geriatric Cognitive Disorders, 19, 276-281. DOI: 10.1159/000084552.

Reisberg, B., Auer, S. R. and Monteiro, I. M. (1996). Behavioral pathology in Alzheimer's disease (BEHAVE-AD) rating scale. International Psychogeriatrics, 8 (Suppl. 3), 301-308.

Robert, P. H. et al. (2005). Grouping for behavioral and psychological symptoms in dementia: clinical and biological aspects. Consensus paper of the European Alzheimer disease consortium. European Psychiatry, 20, 490-496. DOI: 10.1016/j.eurpsy.2004.09.031.

Sandman, P. O., Adolfsson, R., Norberg, A., Nystrom, L. and Winblad, B. (1988). Long-term care of the elderly. A descriptive study of 3600 institutionalized patients in the county of Vasterbotten, Sweden. Comprehensive Gerontology [A], 2, 120-132.

Schneider, L. et al. (2006). Effectiveness of atypical antipsychotic drugs in patients with Alzheimer's disease. New England Fournal of Medicine, 355, 1525-1538.

Sclan, S., Saillon, A., Franssen, E., Hugonot-Diener, L., Saillon, A. and Reisberg, B. (1996). The behavior pathology in Alzheimer's disease rating scale (Behave-AD): reliability and analysis of symptom category scores. International fournal of Geriatric Psychiatry, 11, 819-830. 
Selbaek, G., Kirkevold, O. and Engedal, K. (2007). The prevalence of psychiatric symptoms and behavioural disturbances and the use of psychotropic drugs in Norwegian nursing homes. International fournal of Geriatric Psychiatry, 22, 843-849. DOI: 10.1002/gps.1749.

Shimabukuro, J., Awata, S. and Matsuoka, H. (2005). Behavioral and psychological symptoms of dementia characteristic of mild Alzheimer patients. Psychiatry and Clinical Neurosciences, 59, 274-279.

Shin, I. S., Carter, M., Masterman, D., Fairbanks, L. and Cummings, J. L. (2005). Neuropsychiatric symptoms and quality of life in Alzheimer disease. American fournal of Geriatric Psychiatry, 13, 469-474.

Spalletta, G. et al. (2004). Cognition and behaviour are independent and heterogeneous dimensions in Alzheimer's disease. Fournal of Neurology, 251, 688-695. DOI: 10.1007/S0041500404036.

Suh, G. H. and Kim, S. K. (2004). Behavioral and psychological signs and symptoms of dementia (BPSD) in antipsychotic-naive Alzheimer's disease patients. International Psychogeriatrics, 16, 337-350. DOI: 10.1017/S1041610204000432. 